This is an author produced version of a paper published in Work. This paper has been peer-reviewed but does not include the final publisher proof-corrections or journal pagination.

Citation for the published paper:

Muhonen, Tuija. (2010). Feeling double locked-in at work : Implications for health and job satisfaction among municipal employees. Work, vol. 37, issue 2 , p. null

URL: https://doi.org/10.3233/WOR-2010-1070

Publisher: IOS

This document has been downloaded from MUEP (https://muep.mah.se) / DIVA (https://mau.diva-portal.org). 


\title{
Feeling double locked-in at work - implications for health and job satisfaction among municipal employees
}

\author{
Associate professor Tuija Muhonen \\ Faculty of Culture and Society \\ Dept. of International Migration and Ethnic Relations \\ Malmö University \\ SE-205 06 Malmö \\ Sweden \\ Tel: +46406657531 \\ Fax: +4640665 7330 \\ E-mail: tuija.muhonen@mah.se
}

\section{Citation:}

Muhonen, T. (2010). Feeling double locked-in at work: Implications for health and job satisfaction among municipal employees. Work, 37(2), 199-204.

\begin{abstract}
The aim of the study was to examine the double locked-in phenomenon at work (i.e., being in a non-preferred occupation and non-preferred work place), and its associations to psychological health, physical health and job satisfaction. A total of 136 municipal employees who visited a career coaching center (response rate 59\%) participated in the questionnaire study. The results showed that $61 \%$ of the participants were double locked-in and half of them perceived rather much or very much stress. Multiple regression analyses showed that a feeling of being double locked-in predicted psychological health (GHQ-12) and job satisfaction, even after optimism and perceived stress were controlled for, whereas double locked-in did not predict physical health. This study suggests that the locked-in phenomenon and its underlying causes and consequences need to be studied further in future research. To counteract the negative effects of the double locked-in phenomenon it is important to facilitate employees’ mobility in different ways.
\end{abstract}

Key words: Locked-in at work, health, job satisfaction, optimism, municipal employees 


\section{Introduction}

Long-term sickness absence started to increase considerably in Sweden towards the end of the 20th century, resulting in costs for the individual, the organization and for society [1]. This has been a general problem in Swedish working life, and especially for employees in the municipal sector $[8,26]$, which is responsible for schools, childcare and care of the elderly. This sector is strongly female-dominated, reflecting the gendersegregated labor market in Sweden. In spite of the balance in labor force participation among women and men, gender segregation in the Swedish labor market is still high with regard to sectors, jobs and hierarchical positions [27]. As a result of this segregation, men and women are often exposed to different work environment problems, and women tend to have poorer work environments than men (e.g., women often work in the public sector with human service occupations which can consist of mentally-demanding jobs [8]). Bildt and Michélsen [5] found more occupational risk factors predicting poor mental health for women than for men, suggesting that these findings mirror the gender-segregated labor market. Women are also confronted with additional demands, such as role conflicts and conflicts between work and family responsibilities [7, 15].

The reasons behind increased sickness absence have been considered to relate to the dramatic changes in working life due to internationalization or globalization and technological development leading to outsourcing and downsizing, which in turn has led to increased demands and stress among employees [21]. A stressful working environment, characterized by demands for flexibility and insecurity, may result in further negative outcomes for employees, such as decreased job satisfaction and a lowered level of commitment $[6,28]$.

As a result of the changeable working life, it is more difficult to get a permanent job and this development has made employees in permanent positions more reluctant to shift to other jobs. It has been suggested that the feeling of being locked-in can contribute to illhealth among employees. The term locked-in refers to employees who have tenure, but who are not in their preferred occupation and/or workplace $[2,3,13]$. Those employees who feel that they are neither in their preferred occupation nor preferred workplace are referred to as double locked-in employees. According to previous research, around $28-36 \%$ of the Swedish labor force report that they are not in a preferred occupation or a preferred workplace [2, 3] and 20\% have been classified as double locked-in [2].

Earlier studies have shown inconclusive results concerning gender and the locked-in phenomenon [3, 13], whereas differences related to age, educational level and line of work have been found. Employees who are under 25 years, have little education and/or work in restaurants, in industry or in health care, often feel more locked-in than others [3]. Further, employees in the municipal sector experience being locked-in more frequently than other employees in the public sector. There are also indications that the employees who report being locked-in have more health problems (e.g., headaches, stomach problems, fatigue) than other employees [2, 3]. Being locked-in is also associated with risk for long-term sick leave [13]. On the other hand, Liljegren and Ekberg [20] have found that job mobility has positive effects on employees' health. Aside from the effects on health, it seems that being locked-in also affects the working environment (e.g., such individuals experience less social support and have fewer opportunities for development [3]). This seems to apply particularly for double locked-in employees [2]. 
There could be several reasons why being locked-in is associated with poorer health and it is postulated that one underlying reason might be a lack of control. According to the Demand-Control model [17], it is the combination of high demands and low control at work that is crucial for health, not the demands per se. The importance of perceived control for employees' health has been confirmed in several studies [22, 29]. It is postulated that feeling locked-in can be harmful to health due to the fact that individuals feel that they lack control over the work situation rather than within the work situation as stated in the Demand-Control model [3, 2].

Personality characteristics can also influence how individuals handle different demands related to work and well-being. Optimism (i.e., an individual's generalized expectancy that future outcomes will be good) has been found to be beneficial for both psychological and physical well-being as well as job satisfaction [9, 18]. It appears that optimism can even operate proactively, i.e., optimistic individuals can anticipate stressors and try to ensure actively the positive outcome of the future events $[9,10]$.

There has been limited research about the locked-in phenomenon at work [3] and its relationship to health and organizational outcomes. Furthermore, earlier research has not taken personality factors such as optimism into consideration. The aim of this study is to examine the double locked-in phenomenon at work and its association to psychological health, physical health and job satisfaction among a group of municipal employees. The relative importance of feeling double-locked in for these outcome variables is investigated while controlling for perceived stress and optimism.

\section{Method}

\subsection{Procedure and Participants}

Questionnaires were handed to all (230) municipal employees who visited "Coworker Center", a career coaching center in Western Sweden between March 2007 and March 2008. The Co-worker Center was initially established as a joint venture between eight municipalities in order to improve health among municipal employees who have permanent employment (a total of 17000 employees) by increasing voluntary job mobility. Staff turnover is low (2-4\%), but $10-20 \%$ of the employees would like to change their jobs according to earlier questionnaires. The aim of the Co-worker Center is to act proactively in order to increase job mobility before employees have developed ill-health. After a two-year trial period the Co-worker Center is now run as an independent unit.

Altogether 136 questionnaires were returned by mail to the author, resulting in a response rate of 59\%. The participants represented a wide range of occupations, the largest categories being teachers and assistant nurses. A large majority (89\%) of the participants were women, which can be expected since the municipal sector is female dominated. The mean age of the participants was 47 years $(\mathrm{SD}=8.7)$, most of them were married $(77 \%)$ and $50 \%$ of them had children under 18 years living at home. All of the participants had permanent employment in the municipality and had been working in their current occupation and current workplace for an average of nine years. Most of the participants were not managers (91\%) and did not have university education (56\%). There were no gender differences concerning the background variables. 


\subsection{Measures}

Demographics. The demographic questions included age, gender, marital status, number of children, education $(1=$ university degree or $0=$ not $)$, organizational level $(1=$ managerial position or $2=$ not), number of years in current occupation and current employment.

Locked-in phenomenon. Two questions based on earlier research [2] were used to study the locked-in phenomenon namely, "Is your current workplace the one you would prefer in the future?" and "Is your current occupation the one you would prefer in the future?” Additional four questions were included for those participants who were not in their preferred occupation, namely if they knew which occupation they would prefer; if they had the education required for that occupation; if they were taking actions in order to attain their preferred occupation; and finally, if they would rather have temporary employment in the preferred occupation over permanent employment in their non-preferred occupation.

Optimism. Dispositional optimism was measured by the revised version of The Life Orientation Test (LOT-R) originally developed by Scheier and Carver [23] and revised by Scheier, Carver and Bridges [24]. The LOT-R consists of six items that evaluate generalized expectancies for either positive or negative outcomes. A sample item is: "In uncertain times, I usually expect the best”. Ratings were made on a 5-point scale from 1 (I agree a lot) to 5 (I disagree a lot). Higher scores on the LOT-R are considered to indicate increased optimism $(\alpha=.74)$.

Perceived stress. Stress was assessed by a single question: "Stress means the situation when a person feels tense, restless, nervous, or anxious, or is unable to sleep at night because his mind is troubled all the time. Do you feel that kind of stress these days?” [11]. Response alternatives ranged from 1 (not at all) to 5 (very much).

Job Satisfaction. Six items $(\alpha=.75)$ from the Copenhagen Psychosocial Questionnaire - COPSOQ [19] were used to measure job satisfaction. A sample item is: "How pleased are you with the way your abilities are used?" Respondents rated the items on a four-point scale ranging from 1 (highly unsatisfied) to 4 (very satisfied).

Physical health. Ten items $(\alpha=.82)$ from Subjective Health Complaints - SHC [12] were used to measure physical health. The participants indicated the severity of each complaint (e.g., headache, neck pain, dizziness) on a four-point scale from 0 (none) to 3 (severe).

Psychological health. A Swedish version [25] of the General Health Questionnaire-12 originally developed by Goldberg [14] was used to assess psychological health $(\alpha=.88)$. A sample item is: "I feel myself capable of making decisions". The respondents rated the items on a four-point scale from 0 (Disagree very much) to 3 (Agree very much). Responses are coded so that high values indicate low psychological health.

\section{Results}

\subsection{Initial analysis}


As can be seen in Table 1, only $17 \%$ thought that they were in their preferred occupation and workplace, whereas 61\% reported being double locked-in. Fifty four percent of those who were double locked-in replied that they knew which occupation they would prefer in the future, $37 \%$ of them having the education required for that occupation. The majority (57\%) of the double locked-in stated that they would take action in order to attain their preferred occupation. When it came to the type of employment, a majority (59\%) of the double locked-in would discard temporary employment in their preferred occupation in favor of permanent employment in a non-preferred occupation.

The results also showed that $50 \%$ of the participants perceived rather much or very much stress compared with $15-18 \%$ shown by earlier research [11]. Psychological health measured by GHQ-12 [14, 25] showed a somewhat higher mean value for the participants $(\mathrm{M}=11.81)$ than in earlier studies $(8.53$ - 9.71) conducted by Aronsson, Dallner and Lindh [4].

Table 1 about here

Descriptive statistics and correlations for the study variables are presented in Table 2. There were no significant correlations between the background variables age, gender, educational level and either feeling double locked-in, stress, psychological or physical health or job satisfaction. The feeling of being double locked-in had a significant positive correlation with perceived stress and psychological health and a negative correlation with job satisfaction, indicating that double locked-in employees experienced more stress, poorer psychological health and less job satisfaction than other employees.

Perceived stress was shown to have significant positive correlations with both physical and psychological health and a negative correlation with job satisfaction. Those employees who reported more stress had poorer physical and psychological health and were less satisfied with their jobs. There was a positive significant correlation between optimism and educational level indicating that the employees with university educations scored higher on optimism. Further, optimism was negatively related to perceived stress and to both psychological and physical health.

Table 2 about here

\subsection{Predicting psychological health, physical health and job satisfaction}

In order to examine the role of feeling double locked-in as a predictor of psychological health, physical health and job satisfaction three multiple regression analyses were run on the data. The analyses were conducted in two steps and the results of the multiple regression analyses are presented in Table 3.

In the first step, the demographic variables age, gender and educational level were entered into the analysis. The results showed that none of these variables were significant predictors for psychological health, physical health or job satisfaction.

Table 3 about here 
In the second step of the analysis, the variables optimism and perceived stress were entered as control variables since they were significantly related to all the studied outcome variables in the present study, as well as in previous studies $[9,17,18]$. The results showed that optimism acted as a predictor for only psychological health, whereas perceived stress was a significant predictor for both psychological and physical health, as well as for job satisfaction (i.e., high perceived stress appeared to be related to poorer psychological and physical health and lower job satisfaction).

In the third step, the variable double locked-in was entered in order to examine how much explained variance in the outcome variables could be attributed to it. The results indicated that feeling double locked-in was associated with poorer psychological health and lower job satisfaction, but was not related to physical health. Feeling double locked-in accounted for $3 \%$ of the variation in psychological health and $12 \%$ of the variation in job satisfaction.

\section{Discussion}

The aim of the current study was to investigate the locked-in phenomenon at work and its associations to psychological and physical health and job satisfaction. The results showed that $83 \%$ of the participants experienced being locked-in, and $61 \%$ being double locked-in (i.e., that they were neither in their preferred occupation nor preferred work place). This is a much higher figure compared with an earlier study in a randomly selected group among the Swedish working population showing that $20 \%$ could be classified as being double locked-in [2]. This could be due to the fact that the participants, due to selfselection, consist of a group of municipal employees who were visiting a co-worker center in order to receive career advice.

Contrary to earlier studies [2, 3], the locked-in phenomenon was not related to age or educational level. A large majority of the participants were women and $50 \%$ of them had children less than 18 years of age living at home. Even though earlier studies have not found clear gender differences [3, 13], gender might be one important factor behind the high prevalence of feeling double locked-in at work. The women in this study were working in mentally demanding occupations (e.g., as teachers and nurses [8]), while at the same time their mobility might have been restricted due to family responsibilities since many of them (50\%) had children under 18 years of age living at home.

The results also showed that a high proportion of the participants (50\%) reported feeling rather much or very much stressed as compared with $15-18 \%$ in earlier research [11]. Even the psychological health measured by GHQ-12 [14, 25] was somewhat poorer $(M=11.81)$ in the studied group than that shown in earlier studies $(M=8.53-9.71)$ by Aronsson et al. [4]. This could be related to the high prevalence of being locked-in among the participants in the present study.

Those who felt locked-in reported more stress, poorer psychological health and less job satisfaction than other participants. The results of the multiple regression analyses showed that being double locked-in contributed significantly to the explained variance for both psychological health and job satisfaction, even when optimism and perceived stress were controlled for. 
This study has some limitations that should be taken into consideration. Firstly, this is a relatively small sample consisting of participants who represent a broad range of occupations in the municipal sector, and who had all visited a career coaching center, which can partly explain the higher proportion of locked-in employees in the sample. Another limitation is that the perceived stress was studied by a single-item. Even though it has been proven to have satisfactory content, criterion and construct validity [11], the reliability could have been improved by using a multiple-item measure. And finally, due to the crosssectional design of the study, no causal conclusion can be drawn.

Although the generalizability of the current study is restricted due to the limitations mentioned above, it seems that the problem of feeling locked-in is a substantial one in the Swedish labor market [2]. The double locked-in phenomenon can be regarded as an important factor for employee health and indicates that different kinds of actions should be considered in order to increase employees' mobility. This is especially so when there are indications that increased mobility seems to be related to better health among the employees [20]. Some organizations have started to cooperate (so called 'employer rings') so that they can provide a broad spectrum of professions from which to choose and thereby increase and facilitate voluntary mobility amongst their employees and in the long run prevent long-term sickness absences [16]. Considering that the Swedish labor market is highly gender-segregated, further mobility-enhancing initiatives for all employees should be considered. The locked-in phenomenon, and its underlying causes and consequences need to be studied in more detail in future research.

\section{References}

[1] K. Alexandersson and A. Norlund, Sickness absence: causes, consequences, and physicians' sickness certification practice. A systematic literature review by the Swedish Council on Technology Assessment in Health Care (SBU). Chapter 1. Aim, background, key concepts, regulations, and current statistics, Scandinavian Journal of Public Health, 32(Supplement 63) (2004), 12-20.

[2] G. Aronsson, M. Dallner and K. Gustafsson, Yrkes- och arbetsplatsinlåsning. En empirisk studie av omfattning och hälsokonsekvenser [Locked-in, in the occupation and the working place. An empirical study of prevalence and health consequences], Arbete och hälsa 5 (2000), 1-25.

[3] G. Aronsson and S. Göransson, Permanent employment but not in a preferred occupation: Psychological and medical aspects, research implications, Journal of Occupational Health Psychology 4 (1999), 152-163.

[4] G. Aronsson, M. Dallner and T. Lindh, Flexibla inkomster och fasta utgifter. En studie av ekonomisk stress och hälsa bland korttidsanställda. [A flexible income and fixed expenses. Economic stress among on call-employees], Arbete och Hälsa 20 (2002), 1-26.

[5] C. Bildt and H. Michélsen, Gender differences in the effects from working conditions on mental health: A 4-year follow-up, International Archives of Occupational and Environmental Health 75 (2002), 252-258.

[6] R. J. Burke and C. L. Cooper, The organization in crisis: Downsizing, restructuring and privatization, Oxford: Blackwell Publishers Ltd, 2000. 
[7] R. J. Burke and E. R. Greenglass, Work-family conflict, spouse support, and nursing staff well-being during organizational restructuring, Journal of Occupational and Organizational Psychology 4 (1999), 327-336.

[8] O. Bäckman and C. Edling, Work Environment and Work-related Health Problems in the 1990s, in: Worklife and health in Sweden 2000, S. Marklund, ed, Stockholm: National Institute for Working Life, 2001, pp. 101-117.

[9] C. S. Carver and M. Scheier, Optimism, in: Handbook of positive psychology, C. R. Snyder and S. J. Lopez, eds, New York: Oxford University Press, 2005, pp. 231243.

[10] J. L. Crosno, S. B. Rinaldo, H. G. Black and S. W. Kelley, Half full or half empty. The role of optimism in boundary-spanning positions, Journal of Service Research 11 (2009), 295-309.

[11] A-L. Elo, A. Leppänen, A. Jahkola, Validity of a single-item measure of stress symptoms, Scandinavian Journal of Work, Environment \& Health 29, (2003), 444451.

[12] H. R. Eriksen, C. Ihlebæk and H. Ursin, A scoring system for subjective health complaints (SCH), Scandinavian Journal of Public Health, 1 (1999), 63-72.

[13] G. Fahlén, H. Goine, C. Edlund, B. Arrelöv, A. Knutsson and R. Peter,. Effortreward imbalance, "locked in" at work, and long-term sick leave, International Archives of Occupational and Environmental Health 82 (2009), 191-197.

[14] D. P. Goldberg, The detection of psychiatric illness by questionnaire. Oxford: Oxford University Press, 1972.

[15] E. R. Greenglass, Work stress, coping, and social support: Implications for women's occupational well-being, in: Gender, work stress, and health, D. L. Nelson and R. J. Burke, eds, Washington, DC: American Psychological Association, 2002, pp. 85-96.

[16] P. Juhlin and P. Tengblad, Arbetsgivarringar i Sverige [Employer rings in Sweden]. VINNOVA 11 (2004), 1-98.

[17] R. Karasek and T. Theorell, Healthy Work: Stress, Productivity, and the Reconstruction of Working Life, New York: Basic Books, 1990.

[18] D. H. Kluemper, L. M. Little and T. DeGroot, State or trait: effects of state optimism on job related outcomes, Journal of Organizational Behavior 30 2009, 209-231.

[19] T. S. Kristensen, Copenhagen Psychosocial Questionnaire, Arbete och Hälsa 10 (2001), 10-213.

[20] M. Liljegren and K. Ekberg, The longitudinal relationship between job mobility, perceived organizational justice, and health. BMC Public Health, 8 (2008). 164.

[21] S. Marklund and A. Wikman, Some Trends in Swedish Working Life in the 1990s, in: Worklife and health in Sweden 2000, S. Marklund, ed, Stockholm: National Institute for Working Life, 2001, pp. 7-20.

[22] T. Muhonen and E. Torkelson, The Demand-Control-Support Model and Health among Women and Men in Similar Occupations, Journal of Behavioral Medicine 26 (2003), 601-613. 
[23] M. F. Scheier and C. S. Carver, Effects of optimism on psychological and physical well-being: Theoretical overview and empirical update, Cognitive Therapy and Research 16 (1992), 201-228.

[24] M. F. Scheier, C. S. Carver and M. W. Bridges, Distinguishing optimism from neuroticism (and trait anxiety, self-mastery, and self-esteem): A re-evaluation of the Life Orientation Test, Journal of Personality and Social Psychology 67 (1994), 1063-1078.

[25] C. Sconfienza, Mätning av psykiskt välbefinnande bland ungdomar i Sverige. Användning av GHQ-12. [Measuring mental health among young people in Sweden. The use of GHQ-12], Arbete och hälsa 22 (1998), 1-35.

[26] SOU, Swedish Government Investigation, Ministry of Health and Social Affairs. En handlingsplan för ökad hälsa i arbetslivet 2002:5 (A plan of action for enhancing health at work), Stockholm: Fritzes, 2002.

[27] Statistics Sweden, Women and men in Sweden 2008, Stockholm: Statistics Sweden, 2008.

[28] M. Sverke and J. Hellgren, The nature of job insecurity: Understanding employment uncertainty on the brink of a new millennium, Applied Psychology: An International Review 51 (2002), 23-42.

[29] E. Torkelson and T. Muhonen, Work stress, coping and gender: Implications for health and well-being, in: The individual in the changing working life, K.Näswall, J. Hellgren and M. Sverke, eds, Cambridge: Cambridge University Press, 2008, pp. 311-327. 
Table 1

Frequencies concerning the locked-in phenomenon

\begin{tabular}{lcrrrrrr}
\hline & \multicolumn{7}{c}{ In preferred occupation } \\
& & \multicolumn{1}{c}{ Yes } & & No & \\
& & & $\%$ & $N$ & $\%$ & Total \\
\hline In preferred & Yes & 22 & 17 & 5 & 4 & 27 \\
work place & No & 24 & 18 & 80 & 61 & 104 \\
Total $(N)$ & & 46 & & 85 & & 131 \\
\hline
\end{tabular}


Table 2

Descriptive statistics and correlations for the study variables

\begin{tabular}{lrrrrrrrrrr}
\hline Variable & $M$ & $S D$ & 1 & 2 & 3 & 4 & 5 & 6 & 7 & 8 \\
\hline 1. Age & 47.09 & 8.72 & - & & & & & & \\
2. Gender & 1.89 & .31 & -.12 & - & & & & & \\
3. Educational level & .44 & .50 & .04 & -.07 & - & & & & \\
4. Double Locked-in & .61 & .49 & .01 & .06 & .06 & - & & & \\
5. Optimism & 20.27 & 4.45 & .13 & -.04 & $.19 *$ & -.13 & - & & \\
6. Perceived stress & 3.43 & 1.24 & .09 & .07 & .04 & $.28^{* *}$ & $-.21^{* *}$ & - & & \\
7. Psychological Health & 11.81 & 6.71 & .06 & .10 & -.05 & $.33^{* *}$ & $-.35^{* *}$ & $.63^{* *}$ & - & \\
8. Physical Health & 5.66 & 5.03 & -.01 & .14 & -.07 & .12 & $-.18^{* *}$ & $.40^{* *}$ & $.49^{* *}$ & - \\
9. Job satisfaction & 14.42 & 3.48 & -.13 & -.09 & -.01 & $-.49^{* *}$ & .07 & $-.40^{* *}$ & $-.41^{* *}$ & $-.18^{*}$ \\
\hline
\end{tabular}

Note. Spearman's rho (pairwise deletion of missing values). $N=129-134$. Gender ( 1 = male; $2=$ female); educational level $(0=$ no university education; 1 = university education); double locked-in ( $0=$ no; $1=$ yes); psychological and physical health (higher values indicate poorer health); optimism (higher values indicate increased optimism). ${ }^{*} p<.05,{ }^{* *} p<.01$. 
Table 3

Summary of hierarchical regression analyses predicting psychological health, physiological health and job satisfaction

\begin{tabular}{lccc}
\hline Variables & Psychological health & Physical health & Job satisfaction \\
& $\beta$ & $\beta$ & $\beta$ \\
& & & \\
\hline Step 1 & .04 & .01 & -.07 \\
Age & .02 & .05 & -.12 \\
Gender & .02 & -.05 & .07 \\
Educational level & .01 & .01 & .04 \\
$\Delta R^{2}$ & & & \\
& & & -.01 \\
Step 2 & $-.24^{* *}$ & -.12 & $-.26^{* *}$ \\
Optimism & $.49^{* *}$ & $.37^{* *}$ & $.14^{* *}$ \\
Perceived stress & $.41^{* *}$ & $.18^{* *}$ & \\
$\Delta R^{2}$ & & & $-.37^{* *}$ \\
Step 3 & $.18^{*}$ & .05 & $.12^{* *}$ \\
Double-locked in & $.03^{*}$ & .01 & .30 \\
$\Delta R^{2}$ & .45 & .20 & \\
$R^{2}$ & & & \\
\hline
\end{tabular}

Note. $\mathrm{N}=121 .{ }^{*} p<.05, * * p<.01$ 